\title{
Socioeconomic Factors Responsible for Obesity Hypertension among Bangladeshi Adults
}

\author{
Bhuyan KC* \\ Department of Statistics, Jahangirnagar University, Dhaka, Bangladesh
}

*Corresponding author: KC Bhuyan, Former Professor of Statistics, Jahangirnagar Universty, Dhaka, Bangladesh.

Received Date: March 16, 2020

Published Date: April 06, 2020

\begin{abstract}
s
The analytical results presented here were the outcome of the information collected from 960 adults of ages 18 years and aboveliving in both urban and rural areas. These adults were investigated by some doctors and nurses from and nearby their working places using quota sampling plan with an objective of covering around 70percent diabetic adults so that sufficient obese and hypertension patients were included in the sample. Out of 960 adults 15.1 percent were suffering from hypertension. Among these adults of hypertension, 16.5 percent were obese. The level of obesity and prevalence of hypertension were significantly associated. Thus it was decided to identify the socioeconomic variables responsible for the sufferings of the adults simultaneously from obesity and hypertension. It was evident from the analytical results that age, marital status, physical inactivity, and involvement in sedentary activities were the responsible factors for the simultaneous sufferings of obesity and hypertension. These information were noted from the test of independence of obesity hypertension and socioeconomic variables. Besides these variables, gender, occupation, value of body mass index, and use of can food were also identified as the responsible factors for prevalence of obesity hypertension among the adults. These letter group of variables were identified by discriminant analysis.
\end{abstract}

Keywords: Obesity; Hypertension; Socioeconomic variables; Odds ratio; Standard error of In(odds ratio); Discriminant analysis; Pooled within group correlation

\section{Introduction}

Hypertension is one of the components of non-communicable diseases (NCDs). It is the primary risk factor for cardiovascular disease, including stroke, heart failure, heart attack and aneurysm. The causes of hypertension are diabetes, kidney diseases, nerve damage, overactive thyroid gland, sleep apnoea, pregnancy, obesity, etc. The problem of hypertension is more prevalent among elderly people worldwide and by 2025 the majority of the elderly people will reside in developing countries [1-3]. The disease is rapidly emerging in developing countries $[4,5]$.

Obesity is also prevalent among elderly people and it is influenced by many socioeconomic factors [6-11]. Again, obesity and hypertension are associated and both are in increasing trend among children also [12,13]. Hypertension is highly prevalent among overweight and obese primary care patients $[14,15]$. It is also prevalent among middle aged men and women [16]. Thus, age can be considered as a responsible factor for hypertension. As hypertension is one type of NCDs, it has many risk factors. Some of these risk factors are socioeconomic variables. Prevalence of hypertension, awareness, and risk factors were previously studied by some authors [16-21]. Again, socioeconomic variables are responsible for all types of non-communicable diseases and it was reported in both home and abroad [22-26]. In a separate study, it was reported that obesity and NCDs were significantly associated [27].

The above discussion indicted that obesity and hypertension were associated. Due to this association a question naturally arises which of the socioeconomic variables are more responsible for the prevalence of both the diseases simultaneously among elderly people of Bangladesh. Thus, the objective of this study was to identify the responsible factors for the prevalence of the disease. 


\section{Methodology}

The source of data for the present analysis was the collected information from adults of ages 18 years and above residing in both urban and rural areas of Bangladesh. The investigated adults were 960 . They were available for investigation nearby the working places of some doctors and nurses when they were doing their Master of Public Health degree in American International University- Bangladesh during the academic session 2017 - 18 . These adults were investigated by quota sampling method to cover around $70 \%$ diabetic patients [26]. The objective to cover this amount of diabetic patients was to ensure a good amount of obese hypertension people. For comparative study a good number of normal subjects were also investigated. Finally, 960 adults were interviewed and data were recorded through a pre-designed and pre-tested questionnaire.

The questionnaire contained different questions related to different socioeconomic variables of the respondents and of the families. The main questions for families were related to the monthly family income and monthly family expenditure. The questions for the diabetic adults were related to the duration of disease, disease related health hazard, i.e. eye problem, kidney problem, heart problem, blood pressure, blood sugar, treatment stage of disease, admission into hospital, etc. Beside these, the other questions were related to personal habit, viz. food habit, working habit, physical activity, utilization of time, etc. The collected personal information were residence, religion, marital status, age, height , weight, education, and occupation. Some of the above mentioned variables were qualitative and some are quantitative in nature. For analytical purpose all the variables were measured in nominal scale by assigning numbers. Height and weight were used to measure the level of obesity and level of obesity was measured by the value of
BMI, where BMI was calculated by weight (in kg) divided by height (in meter $^{2}$ ). The respondents were classified as underweight (BMI< 20 ), normal (BMI = 20 and above but less than 25), overweight (BMI $=25$ and above but less than 30 ) and obese (BMI $\geq 30$ ).

At the first step of analysis, association of level of obesity and prevalence of hypertension [if diastolic blood pressure $\geq 85 \mathrm{mmHg}$ and systolic blood pressure $\geq 140 \mathrm{mmHg}$ ] was investigated. The association of socioeconomic variables and prevalence of obesity hypertension were investigated by Chi-square test, where significant association was decided if the p-value of Chi-square statistic is less than or equal to 0.05 . Some adults were more exposed to the disease compared to others. To study this characteristic the odds ratio (O.R.) along with standard error of $\ln ($ O.R.) for a particular level of a social variable compared to the level of the variable which did not create problem for the disease was calculated. Discriminant analysis was done to discriminate the adults suffering from obesity hypertension from other group of adults. Important variables were detected by the higher value of correlation coefficient in absolute form of a variable with the discriminant function scores in discriminating adults $[28,29]$. The analysis was done using the SPSS [Version 25].

\section{Result}

The investigated adults were classified into four groups according to their level of body mass index. There were 8.9 percent underweight respondents. Majority (47.5\%) of the the respondents were of normal weight. The percentage of overweight respondents was 34.1 and the percentage of obese adults was 9.6 percent. Among the obese adults 26.1 percent were suffering from hypertension. It was observed that among the investigated adults, 15.1 percent were suffering from hypertension and 16.5 percent of them were obese (Table 1).

Table 1: Distribution of respondents according to level of obesity and prevalence of hypertension.

\begin{tabular}{|c|c|c|c|c|c|c|}
\hline \multirow{3}{*}{ Level of obesity } & \multicolumn{4}{|c|}{ Prevalence of hypertension } & \multirow{2}{*}{\multicolumn{2}{|c|}{ Total }} \\
\hline & \multicolumn{2}{|c|}{ Yes } & \multicolumn{2}{|c|}{ No } & & \\
\hline & n & $\%$ & n & $\%$ & n & $\%$ \\
\hline Under weight & 8 & 9.4 & 77 & 90.6 & 85 & 8.9 \\
\hline Normal & 62 & 13.6 & 394 & 86.4 & 456 & 47.5 \\
\hline Overweight & 51 & 15.6 & 276 & 84.4 & 327 & 34.1 \\
\hline Obese & 24 & 26.1 & 68 & 73.9 & 92 & 9.6 \\
\hline Total & 145 & 15.1 & 815 & 84.9 & 960 & 100.0 \\
\hline
\end{tabular}

Significant association was noted between level of obesity and prevalence of hypertension. The obese respondents were more than to times exposed to hypertension compared to the adults who were not obese [O.R. = 2.18, S.E $\ln ($ O.R. $)=0.26]$.

In the sample 55.2 percent adults were male and 1.3 percent of them were suffering from obesity hypertension. This percentage among females was 4.0. The females were more than 3 times exposed to the problem compared to that of males [Table 2].

This was also noted from the result of odds ratio [O.R. $=3.08$, S.E $\ln ($ O.R.) $=0.46$ ]. The prevalence of obesity hypertension was significantly different for males and females $\left[\chi^{2}=6.751\right.$, $\mathrm{p}$-value $=0.009]$. The data indicated that 56.5 percent adults were the residence of urban area and 2.4 percent of them were affected by the disease. This percentage among rural adults was 2.6. There was no significant difference in the proportions of prevalence of obesity hypertension among rural and urban residence. This was noted from the Chi-square test $\left[\chi^{2}=0.053, p-\right.$ value $\left.=0.819\right]$. The odds ratio $[\mathrm{O} . \mathrm{R} .=1.10, \mathrm{~S} . \mathrm{E} \ln (\mathrm{O} . \mathrm{R}$. $)=0.41]$ also indicated that both urban and rural adults were similarly exposed to the disease. Among the adults 82.6 percent were Muslims and 2.8 percent of 
them were suffering from obesity hypertension. This percentage among non-Muslim adults was 1.2. There was no significant difference in the proportions of affected adults of both community in respect of the sufferings from obesity hypertension. This was noted from Chi-square test $\left[\chi^{2}=1.107\right.$, p-value $\left.=0.236\right]$. But the odds ratio [O.R. $=2.35$, S.E $\ln ($ O.R. $)=0.74]$ indicated that the Muslim adults were more than two times exposed to the problem compared to that of non-Muslim adults. Among the respondents 69.8 percent were currently married and 3.6 percent of them were suffering from obesity hypertension. None of currently single adult was the patient of obesity and hypertension simultaneously. However, significant association between marital status and prevalence of obesity hypertension was noted by Chi-square test, where $\chi^{2}=$ 10.654 , $\mathrm{p}$-value $=0.001$.

Table 2: Distribution of adults according to prevalence of obesity hypertension and different socioeconomic variables.

\begin{tabular}{|c|c|c|c|c|c|c|}
\hline \multirow{3}{*}{ Socioeconomic Variables } & \multicolumn{4}{|c|}{ Prevalence of Obesity Hypertension } & \multirow{2}{*}{\multicolumn{2}{|c|}{ Total }} \\
\hline & \multicolumn{2}{|c|}{ Yes } & \multicolumn{2}{|c|}{ No } & & \\
\hline & n & $\%$ & n & $\%$ & N & $\%$ \\
\hline \multicolumn{7}{|l|}{ Residence } \\
\hline Rural & 11 & 2.6 & 407 & 97.4 & 418 & 43.5 \\
\hline Urban & 13 & 2.4 & 529 & 97.6 & 542 & 56.5 \\
\hline Total & 24 & 2.6 & 936 & 97.4 & 960 & 100.0 \\
\hline \multicolumn{7}{|l|}{ Gender } \\
\hline Male & 7 & 1.3 & 523 & 98.7 & 530 & 55.2 \\
\hline Female & 17 & 4.0 & 423 & 96.0 & 430 & 44.8 \\
\hline \multicolumn{7}{|l|}{ Religion } \\
\hline Muslim & 22 & 2.8 & 771 & 97.2 & 793 & 82.6 \\
\hline Non-Muslim & 2 & 1.2 & 165 & 98.8 & 167 & 17.4 \\
\hline \multicolumn{7}{|l|}{ Marital status } \\
\hline Currently married & 24 & 3.6 & 646 & 96.4 & 670 & 69.8 \\
\hline Currently single & 0 & 0.0 & 290 & 100.0 & 290 & 30.2 \\
\hline \multicolumn{7}{|l|}{ Age ( in years) } \\
\hline$<20$ & 0 & 0.0 & 28 & 100.0 & 28 & 2.9 \\
\hline $20-30$ & 0 & 0.0 & 162 & 100.0 & 162 & 16.9 \\
\hline $30-40$ & 3 & 1.2 & 247 & 98.8 & 250 & 26.0 \\
\hline $40-50$ & 11 & 4.2 & 253 & 95.8 & 264 & 27.5 \\
\hline $50+$ & 10 & 3.9 & 246 & 96.1 & 256 & 26.7 \\
\hline \multicolumn{7}{|l|}{ Education } \\
\hline Illiterate & 4 & 7.4 & 50 & 92.6 & 54 & 5.6 \\
\hline Primary & 1 & 0.9 & 114 & 99.1 & 115 & 12.0 \\
\hline Secondary & 5 & 2.2 & 224 & 97.8 & 229 & 23.9 \\
\hline Higher & 14 & 2.5 & 548 & 97.5 & 562 & 58.5 \\
\hline \multicolumn{7}{|l|}{ Occupation } \\
\hline $\begin{array}{l}\text { Agriculture and unskilled } \\
\text { labor }\end{array}$ & 2 & 0.8 & 253 & 99.2 & 255 & 26.6 \\
\hline Business and skilled labor & 5 & 3.1 & 156 & 96.9 & 161 & 16.8 \\
\hline Service & 4 & 1.9 & 209 & 98.1 & 213 & 22.2 \\
\hline Housewives and others & 13 & 3.9 & 318 & 96.1 & 331 & 34.5 \\
\hline \multicolumn{7}{|l|}{ Income ( in 000 taka) } \\
\hline$<40$ & 7 & 2.3 & 304 & 97.7 & 311 & 32.4 \\
\hline $40-60$ & 3 & 1.6 & 186 & 98.4 & 189 & 19.7 \\
\hline $60-80$ & 5 & 2.7 & 183 & 97.3 & 188 & 19.6 \\
\hline $80-100$ & 4 & 2.5 & 156 & 97.5 & 160 & 16.7 \\
\hline $100+$ & 5 & 4.5 & 107 & 95.5 & 112 & 11.6 \\
\hline
\end{tabular}




\begin{tabular}{|c|c|c|c|c|c|c|}
\hline $\begin{array}{r}\text { Family expendit } \\
000 \text { taka }\end{array}$ & & & & & & \\
\hline$<30$ & 2 & 1.7 & 114 & 98.3 & 116 & 12.1 \\
\hline $30-50$ & 6 & 2.0 & 289 & 98.0 & 295 & 30.7 \\
\hline $50-70$ & 6 & 2.9 & 202 & 97.1 & 208 & 21.7 \\
\hline $70-90$ & 4 & 2.3 & 173 & 97.7 & 177 & 18.4 \\
\hline $90+$ & 6 & 3.7 & 158 & 96.3 & 164 & 17.1 \\
\hline \multicolumn{7}{|c|}{ Taking restaurant food } \\
\hline Yes & 15 & 3.0 & 478 & 97.0 & 493 & 51.4 \\
\hline No & 9 & 1.9 & 458 & 98.1 & 467 & 48.6 \\
\hline \multicolumn{7}{|c|}{ Habit of taking can food } \\
\hline Yes & 17 & 2.9 & 567 & 97.1 & 584 & 60.8 \\
\hline No & 7 & 1.9 & 369 & 98.1 & 376 & 39.2 \\
\hline Total & 24 & 2.6 & 936 & 97.4 & 960 & 100.0 \\
\hline
\end{tabular}

Among the adults 54.2 percent were of ages 40 years and above and 4.0 percent of them were the patients of both obesity and hypertension simultaneously. Aong the young adults this problem was not noted. However, there was significant differences in the proportions of adults suffering from the disease $\left[\chi^{2}=11.691\right.$, $\mathrm{p}$-value $=0.021]$. The odds ratio [O.R. $=6.13$, S.E. $\ln ($ O.R.) $=0.62$ ] indicated that aged adults were more than 6 times exposed to the problem compared to that of young adults. Among the respondents 58.5 percent were higher educated and 2.5 percent of them were affected by the problem of hypertension and obesity simultaneously. Illiterate adults were only 5.6 percent but higher proportion [0.074]. of them were affected by the disease. But the proportions of adults of different levels of education were statistically similar as was observed by Chi-square test, where $\chi^{2}=6.684$, p-value $=0.083$. However, illiterate adults were more than 3.5 times exposed to the problem compared to the adults of other levels of education [O.R. $=3.53$, S.E $\ln ($ O.R. $)=0.90]$. The investigated adults were classified into 4 categories according to their physical activities. These categories were farmers and unskilled labors (26.6\%), Business persons and skilled labors (16.8\%), service persons (22.2\%) and housewives, students and unemployed persons (34.5\%). This last group of adults were not directly rendering physical labor and 3.9 percent of them were affected by the disease. The next major group of adults $(26.6 \%)$ were agriculturists and unskilled labors. These group of adults had to do physical work and very few $(0.8 \%)$ of them were suffering from obesity hypertension. However, the proportions of affected adults of different occupational pattern were statistically similar as was noted from Chi-square test, where $\chi^{2}=.427$, $\mathrm{p}$-value $=0.093$. But housewives, students and employed adults were more than two times exposed to the problem[O.R.= 2.30, S.E. $\ln ($ O.R. $)=0.42$.

The investigated adults were classified into 5 classes according to their family income. In the lowest income group there were 32.4 percent adults and 2.3 percent of them were affected by obesity hypertension. This percentage of affected adults was higher (4.5\%) in the families having highest income group (11.6\%). However, the proportions of affected adults of different levels of income were statistically similar as was observed by Chi-square test, where $\chi^{2}=$ $2.518, \mathrm{p}$-value $=0.641$. The adults of families having highest income level was more than two times exposed to the problem of obesity hypertension compared to that of adults of other income levels [O.R. $=2.04$. S.E $\ln$ (O.R.) $=0.51]$. The respondents were also classified into 5 classes according to their monthly family expenditure. The lowest monthly family expenditure was less than 30 thousand taka and 12.1 percent adults belonged to these families. The lowest proportion $(1.7 \%)$ of adults of this group were suffering from obesity hypertension. Maximum family expenditure was noted in 17.1 percent families and highest proportion (0.037) of adults of these families were affected by the disease. Though insignificant, there was an increasing trend of proportion of affected adults with the increase in level of family expenditure $\left[\chi^{2}=1.621, \mathrm{p}\right.$ - value $=0.803]$. Adults belonged to families spending highest amount of money were 64 percent more exposed to this health hazard compared to the adults belonged to families of other levels of expenditure [O.R. $=1.64$, S.E. $\ln (\mathrm{O} . \mathrm{R})=$.0.48 .

Depending on family income and expenditure, the family members utilize their money. It was noted that 51.4 percent adults were habituated in taking restaurant food and 3.0 percent of them were affected by prevalence of obesity hypertension. Those who were taking restaurant food (48.6\%) only 1.9 percent of them were suffering from the disease. However, the differentials in proportions of affected adults irrespective of habit of taking restaurant food were not significant $\left[\chi^{2}=1.224, \mathrm{p}\right.$ - value $=0.269$. But adults taking restaurant food were 60 percent more exposed to the problem compared to the adults who were not taking restaurant food. A big group (60.8\%) of adults were habituated in taking can food and 2.9 percent of them were affected by the disease. Lower $(1.9 \%)$ proportion of adults who were not taking can food was suffering from disease. However, there was no significant evidence of association 
of taking can food and suffering from obesity hypertension [ $\chi^{2}$ $=1.033, \mathrm{p}-$ value $=0.399 \mathrm{]}$. The data indicated that 38.6 percent adults were smokers and 1.9 percent of them were affected by the disease. More (2.9\%) non-smokers were suffering from obesity hypertension. However, smoking habit was not statistically associated with the prevalence of obesity hypertension $\left[\chi^{2}=0.933\right.$, $\mathrm{p}-$ value $=0.334 \mathrm{]}$. But non-smokers were 55 percent more exposed to the disease compared to the smoker adults [O.R. $=1.55$, S.E $\mathrm{ln}$ (O.R.) $=0.46$. One of the reason of overweight and obesity is physical inactivity [30]. This study provided the evidence that 63.4 percent adults were not doing any physical work and 3.6 percent of them were suffering from obesity hypertension. There was significant association between prevalence of obesity hypertension and level of physical activity [ $\chi^{2}=8.457$, p-value $\left.=0.004\right]$. Those who did not do any physical work they were more than 6 times exposed to the disease $[$ O.R. $=6.54$, S.E. $\ln ($ O.R. $)=0.74]$.

Wasting time only by reading paper, using mobile phone, and watching television without any physical work is sedentary activity and it is the cause of many diseases [24]. The present data provided the information that 34.7 percent adults passed their time only by reading paper, watching television and using mobile phone and 4.8 percent of them were facing the problem of obesity hypertension. This prevalence was significantly associated with the utilization of time $\left[\chi^{2}=35.841, \mathrm{p}-\right.$ value $\left.=0.000\right]$. The adults involved in sedentary activities were more than 8 times exposed to this health problem compared to the other adults[O.R.=8.32, .E. $\ln ($ O.R. $)=$ 0.43] (Table 3).

\section{Discriminant analysis}

This analysis is performed to identify some most important variables which can discriminate the respondents of different pre-identified groups. The important variables are detected using the pooled within group correlation of a variable with discriminant function scores [9,28-29]. The maximum absolute value of correlation coefficient of a variable indicates the most important variable for discrimination. The present respondents were classified into two groups. In one group there were 24 obese and hypertension patients and in another group there were the remaining 936 adults including some normal subjects. Discriminant analysis was done to discriminate these two groups of adults so that some variables could be identified as responsible factors for discrimination. The analytical results (Table 3) showed that the most responsible variable for discrimination was body mass index followed by utilization of time by the adults, marital status, physical work and gender. These variables were significantly associated with the prevalence of obesity hypertension. The p-values in doing one-way analysis of variance (Table 3) also indicated that these variables were significantly different for both groups of adults under study. The discriminant analysis was also significant as Wilk's $\Lambda=0.805$ giving Chi-square $=206.698$ with $p$-value $=0.000$.

\begin{tabular}{|c|c|c|c|c|c|}
\hline Variables & Wilk"s A & F & p-values & $\begin{array}{c}\text { Unstandardized } \\
\text { Coefficient }\end{array}$ & $\begin{array}{c}\text { Correlation } \\
\text { coefficient }\end{array}$ \\
\hline Residence & 1.000 & 0.052 & 0.819 & -0.019 & -0.015 \\
\hline Religion & 0.999 & 1.406 & 0.236 & -0.078 & -0.078 \\
\hline Gender & 0.993 & 6.784 & 0.009 & 1.036 & $0.171^{*}$ \\
\hline Age & 0.995 & 4.967 & 0.026 & 0.077 & $-0.215^{*}$ \\
\hline Marital status & 0.989 & 10.752 & 0.001 & -0.081 & -0.052 \\
\hline Education & 0.999 & 0.640 & 0.424 & -0.121 & $0.141^{*}$ \\
\hline Occupation & 0.995 & 4.619 & 0.032 & -0.060 & 0.069 \\
\hline Income & 0.999 & 1.029 & 0.311 & -0.796 & 0.093 \\
\hline Expenditure & 0.998 & 2.003 & 0.157 & 0.746 & -0.073 \\
\hline Food habit & 0.999 & 1.223 & 0.269 & 0.002 & 0.003 \\
\hline Smoking habit & 0.999 & 0.932 & 0.335 & -1.001 & -0.069 \\
\hline Taking can food & 0.999 & 1.032 & 0.310 & -0.145 & $-0.191^{*}$ \\
\hline Physical work & 0.991 & 8.514 & 0.004 & 0.063 & $0.293^{*}$ \\
\hline Utilization of time & 0.980 & 19.896 & 0.000 & 0.803 & $0.822^{*}$ \\
\hline Body mass index & 0.859 & 157.191 & 0.000 & -4.185 & - \\
\hline Constant & - & - & - & \\
\hline
\end{tabular}

\section{Discussion}

The paper contained the analytical results of data collected from 960 adults of ages 18 years and above residing in both urban and rural areas of Bangladesh. Data were collected by some doctors and nurses from and nearby their working places under the quota sampling plan to cover around 70 percent [16] diabetic patients so that sufficient number of adults of different diseases including diabetes were found out for different types of analysis. Among the adults 145 were patients of hypertension and 24 of them were obese. These 24 adults were suffering from obesity and hypertension simultaneously. During analysis it was noted that prevalence of hypertension and level of obesity were significantly 
associated and obese adults were more than two times exposed to the problem of hypertension. Thus the plan of the study was to investigate the association of different socioeconomic variables with the simultaneous prevalence of hypertension and obesity.

As the data were collected from and nearby the working places of some doctors and nurses, most of the investigated adults (56.5\%) were from urban area. The rural adults were 43.5 percent. But higher proportion of them were suffering from the disease, though urban and rural adults were similarly exposed to the disease [O.R. $=1.10]$. Muslim adults were higher in percentage (82.6\%) and bigger group of them were suffering from the disease compared to the sufferers among non-Muslim adults. The Muslim adults were more than two times exposed to the disease [O.R. $=2.35$ ]. Physical inactivity is the cause of many diseases and females are not directly rendering physical labor[21, 30 - 32], so they are more exposed to any type of diseases. In this study, it was noted that 44.8 percent adults were females and 4.0 percent of them were suffering from the disease. The females were more than 3 times exposed to the disease compared to the males. Similar was the case for housewives, students and unemployed adults.

The prevalence of hypertension was noted among elderly people of Bangladesh and India [20]. This analysis showed that out of 24 patients suffering from obesity hypertension 21 were of ages 40 years and above. This indicated that the elderly people were at higher risk of the disease. The elderly people ( 40 years and above) were more than 6 times exposed to the disease compared to the younger adults. Similar result was noted in abroad also [16]. In some studies, in both home and abroad, it was noted that there was decreasing trend in the prevalence of non-communicable diseases with the increase in level of education $[7,8,27,31,32]$. The adults investigated for the present analysis were mostly at least graduate $(58.5 \%)$. But level of education was not statistically associated with prevalence of obesity hypertension. However, illiterate adults were 353 percent more exposed to the disease compared to literate adults. Family income and family expenditure were not influencing factors to enhance the problem of obesity hypertension, though these two social factors had positive impact in enhancing the NCDs $[9,31,32]$. The present analysis showed an upward trend in the percentages of affected adults with the increase in levels of income and expenditure. The adults of higher income level and higher expenditure level were more exposed to this health problem.

Habit of taking restaurant food, can food and processed food, smoking habit and physical inactivity were responsible variables for many of the non-communicable diseases [9,22,23,25,27,31,32]. But the present analysis indicated that only physical inactivity was significantly associated with the prevalence of obesity hypertension and inactive adults were more than 6 times exposed to this health hazard compared to the adults doing physical work. Adults taking restaurant food and can food were also more exposed to this health problem. These foods are salt rich food and high fat food and these are risk factors for hypertension $[16,17]$. Physical inactivity and habit of wasting time by watching television or using mobile phone are the sedentary activities and those who were involved in these activities were at higher risk of the obesity hypertension. It was also noted in some studies [16,17]. Adults involved in sedentary activities were more than 8 times exposed to the disease.

The influences of some of the socioeconomic variables on prevalence of obesity hypertension were studied from the results of Chi-square tests. But this test does not provide any information about the magnitude of the association or influence. To identify the most responsible variables for the prevalence of obesity hypertension discriminant analysis was done. This analysis showed that the adults suffering simultaneously from obesity and hypertension were significantly different from other adults and level of body mass index was the most responsible factors followed by utilization of time, marital status, physical inactivity, gender,age and occupation for this discrimination.

\section{Conclusion}

The information contained in this paper were the outcomes of the analysis of data collected from 960 adults of ages 18 years and above residing in both urban and rural areas of Bangladesh. The data were collected by some doctors and nurses when they were doing their M.P.H. degree during academic session 2017-18 using quota sampling plan to cover around 70 percent diabetic patients so that sufficient number of adults suffering from different NCDs were included in the sample [26]. Out of 960 adults 145 were patients of hypertension and 24 of them were suffering simultaneously from hypertension and obesity. In earlier studies, it was observed that some of the socioeconomic variables were influencing factors for these two diseases and some patients were suffering from both the diseases simultaneously $[7,9,12,31,32]$. The present study was planned to investigate the influences of different socioeconomic variables on patients who were suffering from both the diseases simultaneously.

In thesample there were 56.5 percent urban adults. The percentages of males, Muslims, currently married, aged (40 years andabove), higher educated, physically inactive(housewives, students, and unemployed), and obese adults were, respectively $55.2,82.6,69.8,54.2,58.5,63.4,9.6$. In all cases bigger proportion of adults were simultaneously suffering from both the diseases. But significantly differential proportions were observed for the variables age , marital status and physical inactivity. The percentage of adults involved in sedentary activities was 37.7 and 4.8 percent of them were suffering simultaneously from both the disease against 2.5 percent adults of this category in the sample. However, most influencing factors for the prevalence of this disease was body mass index followed by utilization of time, marital status, gender, physical work, age , occupation, etc. These were detected as responsible variables for the variation in the levels of obesity hypertension. This latter group of variables were identified by discriminant analysis.

The analysis indicated that age, sex, sedentary lifestyle, taking restaurant and can food which are salt rich food and high fat food, 
were the risk factors for the diseases.The effects of these variables cannot be avoided but there should be some steps so that the intensity of influences of these variables can be reduced. This can be done by motivating the people so that they are encouraged to avoid their sedentary lifestyle and can start to live for healthy and disease free life. Government, health planners and health workers can go to some extent to motivate the people. For the prevention of the disease the following steps can be taken.

a. There should be some motivation campaignin both urban and rural areas to explain the need of better health management. The campaign should repeated several times as per as possible,

b. People should be advised to do regular physical exercise and to do some physical labor,

c. The physical exercise and physical labor will be helpful in reducing stress,

d. People should be advised to avoid restaurant food, can and processed food, foods of high calorie and foods rich in salt and fat,

e. People should be advised to avoid watching television as per as possible,

f. Whenever need, doctors can be consulted for proper medication,

g. Body weight should be controlled,

h. More vegetables and fresh fruits are to be taken as per as possible

\section{Acknowledgement}

None.

\section{Conflict of Interest}

No conflict of interest.

\section{References}

1. United Nations World Population Projection to 2150 (1998): Population and Development Review 24: 183-189.

2. Kumar V (1997) Ageing in India - Overview, Indian Journal of Medical Research 106: 257-264.

3. National High Blood Pressure Education Program Working Group (1997): Report on hypertension in the Elderly 23: 275-285.

4. Burt VL, Whelton P, Roccella EJ, Brown C, Cutler JA, et al (1995) Prevalence of hypertension in the S adult population, results from the third National Health and Nutrition Examination Survey, 1988- 1991. Hypertension 5: 305-313.

5. Reddy KS, Yusuf S (1998) Emerging epidemic of cardiovascular disease in developing countries, Circulation 97: 596-601.

6. WHO (2007) The challage of obesity in the WHO European region and the strategies for response. In: Branca F, Nikogosian H, Lobstein T Copenhagen.

7. Bertino M, Ardiri AM, Ali FT, Boemi PMS, Cilio D, et al. (2006) Obesity and related disease: an epidemiological study in Eastern Sicily. Minerva Gastroenterol Dietol 52(4): 379-385.
8. Calamusa G, Amodio E, Costantino C, Maria D, Pasquate, et al. (2012) Body mass index and factors associated with overweight and obesity: a cross-sectional study of adult subjects living in a small city of Western Sicily (Italy ), Italian Journal of Pub. Health 9(3): e539.

9. Bhuyan KC, Jannatul F (2019) Discriminating Bangladeshi adults by level of obesity. LOJ Med Sci 3(1): 184-191.

10. Hu FB, Wang B, Chen C, Jin Y, Yang J, et al. (2000) Body mass index and cardiovascular risk factors in a rural Chinese Population. Amer Jour Epideo 151: 88-97.

11. Stamler J (1991) Epidemiological findings on body mass and blood pressure in adults. Annals of Epidemiology 1: 347-362.

12. Bhuyan KC (2020) Discriminating Bangladeshi adults by the prevalence of diabetic hypertension, Unpublished Research Note.

13. Tammy M Brady (2017) Obesity- related hypertension in children, Front Pediatric.

14. Parker ED, Sinaiko AR, Kharbanda EO, Margolis KL, Daley MF, et al. (2016): Change in weight status and development of hypertension, Pediatrics 137.

15. Bramlage P, Pittrow D, Wittchen HU, Kirch W, Boehler S, et al. (2004) Hypertension in overweight and obese primary care patients is highly prevalent and poorly controlled. Amer Jour Hypertension 17: 904- 910.

16. Vasan Rs, Beiser A, Seshadri S, Larson MG, Kannl WB, et al. (2002) Residual lifetime risk for developing hypertension in middle-aged women and men : The Framingham Heart Study. JAMA 287(8): 10031010 .

17. Jugal K, Gupta N, Kohli C, Kumar N (2016) Prevalence of hypertension and determination of its risk factors in rural Delhi, International Journal of Hypertension.

18. Shikha S, Ravi S, Singh GP (2017) Prevalence and associated risk factors of hypertension : A cross-sectional study in urban Varanasi. Int Jour Hypertension 5491838.

19. Chobanian AV, Bakris GL, Black HR, Cushman WC, Green LA, et al (2003) Seventh Report of the Joint National Committee of Prevantion, Detection, Evaluational Treatment of High Blood Pressure. Hypertension 42(6): 1206-1252.

20. WHO (2001) Prevalence, awareness, treatment and control of hypertension among elderly in Bangladesh and India: a multicentre study.

21. Everett B, Zajacova A (2015) Gender difference in hypertension and hypertension awareness among young adults, Biodemography and Social Biology 61(1): 1-17.

22. Akter S, Rahaman MM, Sarah KA, Sultan P (2014) Prevalence of diabetes and pre-diabetes and their risk factors among Bangladeshi adults: A Nationwide survey, Bulletin of the WHO 92: 204-213.

23. Mokdad AH, Ford ES, Bowman BA, Dietz WH, Vinicor F, et al. (2003) Prevalence of obesity, diabetes, and obesity-related health risk factors 2001. JAMA 289: 76-79.

24. Bhuyan KC, Fardus J (2019) Level of obesity and socioeconomic factors of a group of adult people of Bangladesh: A factor analysis approach, Amer, Jour. Data Mining and Knowledge Discovery 4(1): 8-14.

25. Bhuiyan D, Bhuyan KC (2019) Discriminating Bangladeshi adults by non-communicable diseases, Rehabilitation Science 4(3): 35-43.

26. Fardus J, Bhuyan KC (2016) Discriminating diabetic patients of some rural and urban areas of Bangladesh: A discriminant analysis approach, Euromediterrean Bio Jour 11(9): 134-140.

27. Bhuyan KC (2019) Factors Responsible for Non-communicable Diseases Except Diabetes among Bangladesh Adults, Archives of Diabetes and Endocrine System 2(12): 22-29.

28. Bhuyan KC (2004) Multivariate Analysis and its Applications, New Central Book Agency(P) ltd. India. 
29. Bhuyan KC (2019) A note on the application of discriminant analysis in medical research, Archives of diabetes and obesity 2(2): 142-146.

30. Syed MS, Debra N, Muhammad HR, Musa R, Gul N ((2004) Assessing obesity and overweight in a high mountain Pakistani population, Tropical Medicine and International Health 9(4): 526-532.
31. Bhuyan KC (2020) Socioeconomic variables responsible for diabetic retinopathy among Bangladeshi adults. BJSTR 25(1): 18829-18836.

32. Bhuyan KC (2020) Identification of socioeconomic variables responsible for diabetic heart disease among Bangladeshi adults. ARC Journal of Diabetes and Endocrinology 5(2): 1-8. 